\title{
A New Approach to the Approximation of Common Fixed Points of an Infinite Family of Relatively Quasinonexpansive Mappings with Applications
}

\author{
Wei-Qi Deng \\ College of Statistics and Mathematics, Yunnan University of Finance and Economics, Yunnan, \\ Kunming 650221, China
}

Correspondence should be addressed to Wei-Qi Deng, dwq1273@126.com

Received 23 June 2012; Revised 16 August 2012; Accepted 21 August 2012

Academic Editor: Simeon Reich

Copyright (C) 2012 Wei-Qi Deng. This is an open access article distributed under the Creative Commons Attribution License, which permits unrestricted use, distribution, and reproduction in any medium, provided the original work is properly cited.

By using a specific way of choosing the indexes, we propose an iteration algorithm generated by the monotone CQ method for approximating common fixed points of an infinite family of relatively quasinonexpansive mappings. A strong convergence theorem without the stronger assumptions of the AKTT condition and the *AKTT condition imposed on the involved mappings is established in the framework of Banach space. As application, an iterative solution to a system of equilibrium problems is studied. The result is more applicable than those of other authors with related interest.

\section{Introduction}

Let $C$ be a nonempty and closed convex subset of a real Banach space $E$. A mapping $T: C \rightarrow$ $E$ is said to be nonexpansive if

$$
\|T x-T y\| \leq\|x-y\|, \quad \forall x, y \in C .
$$

A mapping $T$ is said to be quasi-nonexpansive if $F(T):=\{x \in C: x=T x\} \neq \emptyset$ and

$$
\|T x-p\| \leq\|x-p\|, \quad \forall x \in C, p \in F(T) .
$$


It is easy to see that if $T$ is nonexpansive with $F(T) \neq \emptyset$, then it is quasi-nonexpansive. There are many methods for approximating fixed points of quasi-nonexpansive mappings. In 1953, Mann [1] introduced the iteration as follows: a sequence $\left\{x_{n}\right\}$ is defined by

$$
x_{n+1}=\alpha_{n} x_{n}+\left(1-\alpha_{n}\right) T x_{n}
$$

where the initial element $x_{0} \in C$ is arbitrary and $\left\{\alpha_{n}\right\}$ is a sequence of real numbers in $[0,1]$. Approximation of fixed points of nonexpansive mappings via Mann's algorithm has extensively been investigated. One of the fundamental convergence results was proved by Reich [2]. In infinite-dimensional Hilbert spaces, Mann iteration can yield only weak convergence (see $[3,4]$ ).

Attempts to modify the Mann iteration method (1.3) for strong convergence have recently been made. Nakajo and Takahashi [5] proposed the following modification of Mann iteration method (1.3) for a nonexpansive mapping $T$ from $C$ into itself in a Hilbert space: from an arbitrary $x_{0} \in C$,

$$
\begin{gathered}
y_{n}=\alpha_{n} x_{n}+\left(1-\alpha_{n}\right) T x_{n}, \\
C_{n}=\left\{z \in C:\left\|y_{n}-z\right\| \leq\left\|x_{n}-z\right\|\right\}, \\
Q_{n}=\left\{z \in C:\left\langle x_{n}-z, x_{0}-x_{n}\right\rangle \geq 0\right\}, \\
x_{n+1}=P_{C_{n} \cap Q_{n}} x_{0}, \quad \forall n \geq 0,
\end{gathered}
$$

where $P_{K}$ denotes the metric projection from a Hilbert space $H$ onto a closed convex subset $K$ of $H$. They proved that the sequence $\left\{x_{n}\right\}$ converges strongly to $P_{F(T)} x_{0}$.

Recently, Su and Qin [6] introduced a monotone CQ method for nonexpansive mapping, defined as follows: from an arbitrary $x_{0} \in C$,

$$
\begin{gathered}
y_{n}=\alpha_{n} x_{n}+\left(1-\alpha_{n}\right) T x_{n}, \\
C_{0}=\left\{z \in C:\left\|y_{0}-z\right\| \leq\left\|x_{0}-z\right\|\right\}, \quad Q_{0}=C, \\
C_{n}=\left\{z \in C_{n-1} \cap Q_{n-1}:\left\|y_{n}-z\right\| \leq\left\|x_{n}-z\right\|\right\}, \\
Q_{n}=\left\{z \in C_{n-1} \cap Q_{n-1}:\left\langle x_{n}-z, x_{0}-x_{n}\right\rangle \geq 0\right\}, \\
x_{n+1}=P_{C_{n} \cap Q_{n}} x_{0}, \quad \forall n \geq 0
\end{gathered}
$$

and it proved that the sequence $\left\{x_{n}\right\}$ converges strongly to $P_{F(T)} x_{0}$.

We now recall some definitions concerning relatively quasi-nonexpansive mappings. Let $E$ be a real smooth Banach space with norm $\|\cdot\|$ and let $E^{*}$ be the dual of $E$. The normalized duality mapping $J$ from $E$ to $E^{*}$ is defined by

$$
J x=\left\{f \in E^{*}:\langle x, f\rangle=\|x\|^{2}=\|f\|^{2}\right\}, \quad \forall x \in E,
$$


where $\langle\cdot, \cdot\rangle$ denotes the pairing between $E$ and $E^{*}$. Readers are directed to [7] (and its review $[8]$ ), where the properties of the duality mapping and several related topics are presented. The function $\phi: E \times E \rightarrow \mathrm{R}^{+}$is defined by

$$
\phi(x, y)=\|x\|^{2}-2\langle x, J y\rangle+\|y\|^{2}, \quad \forall x, y \in E
$$

Let $T$ be a mapping from $C$ into $E$. A point $p$ in $C$ is said to be an asymptotic fixed point [9] of $T$ if $C$ contains a sequence $\left\{x_{n}\right\}$ which converges weakly to $p$ and $\lim _{n \rightarrow \infty}\left(x_{n}-T x_{n}\right)=0$. The set of asymptotic fixed points of $T$ is denoted by $\widehat{F}(T)$.

We say that the mapping $T$ is relatively nonexpansive (see [10]) if the following conditions are satisfied:

(R1) $F(T) \neq \emptyset$;

(R2) $\phi(p, T x) \leq \phi(p, x), \forall p \in F(T)$;

(R3) $F(T)=\widehat{F}(T)$.

If $T$ satisfies (R1) and (R2), then $T$ is called relatively quasi-nonexpansive.

Several articles have provided methods for approximating fixed points of relatively quasi-nonexpansive mappings [11-16]. Employing the ideas of Su and Qin [6], and of Aoyama et al. [17], in 2008, Nilsrakoo and Saejung [18] used the following iterations to obtain strong convergence theorems for common fixed points of a countable family of relatively quasi-nonexpansive mappings in a Banach space

$$
\begin{gathered}
x_{0} \in C, \quad C_{-1}=Q_{-1}=C ; \\
y_{n}=J^{-1}\left(\alpha_{n} J x_{n}+\left(1-\alpha_{n}\right) J T_{n} x_{n}\right), \\
C_{n}=\left\{z \in C_{n-1} \cap Q_{n-1}: \phi\left(z, y_{n}\right) \leq \phi\left(z, x_{n}\right)\right\}, \\
Q_{n}=\left\{z \in C_{n-1} \cap Q_{n-1}:\left\langle x_{n}-z, J x_{0}-J x_{n}\right\rangle \geq 0\right\}, \\
x_{n+1}=\prod_{n} x_{0}, \quad \forall n \geq 0 .
\end{gathered}
$$

However, the results were obtained under two stronger assumption conditions, namely, the $A K T T$-condition and the ${ }^{*} A K T T$-condition imposed on the involved mappings.

Inspired and motivated by those studies mentioned above, in this paper, we use a modified type of the iteration scheme (1.8) for approximating common fixed points of an infinite family of relatively quasi-nonexpansive mappings; without stronger assumptions imposed on the involved mappings, a strong convergence theorem in Banach spaces is obtained for solving a system of equilibrium problems. The results improve those of other authors with related interest. 


\section{Preliminaries}

Throughout the paper, let $E$ be a real Banach space. We say that $E$ is strictly convex if the following implication holds for $x, y \in E$ :

$$
\|x\|=\|y\|=1, \quad x \neq y \Longrightarrow\left\|\frac{x+y}{2}\right\|<1 .
$$

It is also said to be uniformly convex if for any $\epsilon>0$, there exists a $\delta>0$ such that

$$
\|x\|=\|y\|=1, \quad\|x-y\| \geq \epsilon \Longrightarrow\left\|\frac{x+y}{2}\right\| \leq 1-\delta .
$$

It is known that if $E$ is uniformly convex Banach space, then $E$ is reflexive and strictly convex. A Banach space $E$ is said to be smooth if

$$
\lim _{t \rightarrow 0} \frac{\|x+t y\|-\|x\|}{t}
$$

exists for each $x, y \in S(E):=\{x \in E:\|x\|=1\}$. In this case, the norm of $E$ is said to be Gâteaux differentiable. The space $E$ is said to have uniformly Gâteaux differentiable norm if for each $y \in S(E)$; the limit (2.3) is attained uniformly for $x \in S(E)$. The norm of $E$ is said to be Fréchet differentiable if for each $x \in S(E)$; the limit (2.3) is attained uniformly for $y \in S(E)$. The norm of $E$ is said to be uniformly Fréchet differentiable (and $E$ is said to be uniformly smooth) if the limit (2.3) is attained uniformly for $x, y \in S(E)$.

We also know the following properties (see, e.g., [19] for details).

(1) $E\left(E^{*}\right.$, resp.) is uniformly convex $\Leftrightarrow E^{*}(E$, resp.) is uniformly smooth.

(2) $J x \neq \emptyset$ for each $x \in E$.

(3) If $E$ is reflexive, then $J$ is a mapping from $E$ onto $E^{*}$.

(4) If $E$ is strictly convex, then $J x \cap J y=\emptyset$ as $x \neq y$.

(5) If $E$ is smooth, then $J$ is single-valued.

(6) If $E$ has a Fréchet differentiable norm, then $J$ is norm-to-norm continuous.

(7) If $E$ is uniformly smooth, then $J$ is uniformly norm-to-norm continuous on each bounded subset of $E$.

(8) If $E$ is a Hilbert space, then $J$ is the identity operator.

Let $E$ be a smooth Banach space. The function $\phi: E \times E \rightarrow \mathrm{R}^{+}$is defined by

$$
\phi(x, y):=\|x\|^{2}-2\langle x, J y\rangle+\|y\|^{2} .
$$

It is obvious from the definition of the function $\phi$ that

$$
(\|x\|-\|y\|)^{2} \leq \phi(x, y) \leq(\|x\|+\|y\|)^{2} .
$$

Moreover, we know the following results. 
Lemma 2.1 (see [13]). Let E be a strictly convex and smooth Banach space, then $\phi(x, y)=0$ if and only if $x=y$.

Lemma 2.2 (see [11]). Let E be a uniformly convex and smooth Banach space and let $r>0$. Then there exists a continuous, strictly increasing, and convex function $g:[0,2 r] \rightarrow[0, \infty)$ such that $g(0)=0$ and

$$
g(\|x\|-\|y\|) \leq \phi(x, y)
$$

for all $x, y \in B_{r}:=\{z \in E: P z P \leq r\}$.

Let $C$ be a nonempty and closed convex subset of $E$. Suppose that $E$ is reflexive, strictly convex, and smooth. It is known in [20] that for any $x \in E$, there exists a unique point $x^{*} \in C$ such that

$$
\phi\left(x^{*}, x\right)=\min _{y \in C} \phi(y, x)
$$

Following Alber [21], we denote such an $x^{*}$ by $\Pi_{C} x$. The mapping $\Pi_{C}$ is called the generalized projection from $E$ onto $C$. It is easy to see that in a Hilbert space, the mapping $\Pi_{C}$ coincides with the metric projection $P_{C}$. What follows are the well-known facts concerning the generalized projection.

Lemma 2.3 (see [20]). Let $C$ be a nonempty closed convex subset of a smooth Banach space $E$ and let $x \in E$. Then

$$
x^{*}=\Pi_{C} x \Longleftrightarrow\left\langle x^{*}-y, J x-J x^{*}\right\rangle \geq 0, \quad \forall y \in C .
$$

Lemma 2.4 (see [20]). Let $E$ be a reflexive, strictly convex, and smooth Banach space, let $C$ be a nonempty closed convex subset of $E$, and let $x \in E$. Then

$$
\phi\left(y, \Pi_{C} x\right)+\phi\left(\Pi_{C} x, x\right) \leq \phi(y, x), \quad \forall y \in C
$$

Dealing with the generalized projection from $E$ onto the fixed point set of a relatively quasi-nonexpansive mapping, we have the following result.

Lemma 2.5 (see [18]). Let E be a strictly convex and smooth Banach space, let $C$ be a nonempty and closed convex subset of $E$, and let $T$ be a relatively quasi-nonexpansive mapping from $C$ into $E$. Then $F(T)$ is closed and convex.

Let $C$ be a subset of a Banach space $E$ and let $\left\{T_{n}\right\}$ be a family of mappings from $C$ into $E$. For a subset $B$ of $C$, we say that

(i) $\left(\left\{T_{n}\right\}, B\right)$ satisfies AKTT-condition if

$$
\sum_{n=1}^{\infty} \sup \left\{\left\|T_{n+1} z-T_{n} z\right\|: z \in B\right\}<\infty
$$


(ii) $\left(\left\{T_{n}\right\}, B\right)$ satisfies ${ }^{*}$ AKTT-condition if

$$
\sum_{n=1}^{\infty} \sup \left\{\left\|J T_{n+1} z-J T_{n} z\right\|: z \in B\right\}<\infty
$$

\section{Main Results}

Recall that an operator $T$ in a Banach space is closed if $x_{n} \rightarrow x$ and $T x_{n} \rightarrow y$ as $n \rightarrow \infty$, then $T x=y$.

Theorem 3.1. Let $E$ be a uniformly convex and uniformly smooth Banach space, $C$ a nonempty and closed convex subset of $E$. Let $\left\{T_{i}\right\}_{i=1}^{\infty}: C \rightarrow E$ be a sequence of closed and relatively quasinonexpansive mappings with $F:=\bigcap_{i=1}^{\infty} F\left(T_{i}\right) \neq \emptyset$. Starting from an arbitrary $x_{1} \in C$, the sequence $\left\{x_{n}\right\}$ is define by

$$
\begin{gathered}
x_{1} \in C, \quad C_{0}=Q_{0}=C ; \\
y_{n}=J^{-1}\left(\alpha_{n} J x_{n}+\left(1-\alpha_{n}\right) J T_{i_{n}} x_{n}\right), \\
C_{n}=\left\{z \in C_{n-1} \cap Q_{n-1}: \phi\left(z, y_{n}\right) \leq \phi\left(z, x_{n}\right)\right\}, \\
Q_{n}=\left\{z \in C_{n-1} \cap Q_{n-1}:\left\langle x_{n}-z, J x_{1}-J x_{n}\right\rangle \geq 0\right\}, \\
x_{n+1}=\prod_{n} x_{1}, \quad \forall n \geq 1,
\end{gathered}
$$

where $\Pi_{n}:=\Pi_{C_{n} \cap Q_{n}}$ and $\left\{\alpha_{n}\right\}$ is a sequence in $[0,1)$ with $\limsup _{n \rightarrow \infty} \alpha_{n}<1 ; i_{n}$ is the solution to the positive integer equation: $n=i+(m-1) m / 2 \quad(m \geq i, n=1,2, \ldots)$, that is, for each $n \geq 1$, there exists a unique $i_{n}$ such that

$$
\begin{gathered}
i_{1}=1, \quad i_{2}=1, \quad i_{3}=2, \quad i_{4}=1, \quad i_{5}=2, \quad i_{6}=3, \quad i_{7}=1, \quad i_{8}=2, \\
i_{9}=3, \quad i_{10}=4, \quad i_{11}=1, \ldots .
\end{gathered}
$$

Then $\left\{x_{n}\right\}$ converges strongly to $\Pi_{F} x_{1}$.

Proof. We first claim that both $C_{n}$ and $Q_{n}$ are closed and convex. This follows from the fact that $\phi\left(z, y_{n}\right) \leq \phi\left(z, x_{n}\right)$ is equivalent to the following:

$$
2\left\langle z, J x_{n}-J y_{n}\right\rangle \leq\left\|x_{n}\right\|^{2}-\left\|y_{n}\right\|^{2}
$$

It is clear that $F \subset C=C_{0} \cap Q_{0}$. Next, we show that

$$
F \subset C_{n} \cap Q_{n}, \quad \forall n \geq 1
$$


Suppose that $F \subset C_{k-1} \cap Q_{k-1}$ for some $k \geq 2$. Letting $p \in F$, we then have

$$
\begin{aligned}
\phi\left(p, y_{k}\right) & =\phi\left(p, J^{-1}\left(\alpha_{k} J x_{k}+\left(1-\alpha_{k}\right) J T_{i_{k}}-x_{k}\right)\right) \\
& =\|p\|^{2}-2\left\langle p, \alpha_{k} J x_{k}+\left(1-\alpha_{k}\right) J T_{i_{k}} x_{k}\right\rangle+\left\|\alpha_{k} J x_{k}+\left(1-\alpha_{k}\right) J T_{i_{k}} x_{k}\right\|^{2} \\
& \leq\|p\|^{2}-2 \alpha_{k}\left\langle p, J x_{k}\right\rangle-2\left(1-\alpha_{k}\right)\left\langle p, J T_{i_{k}} x_{k}\right\rangle+\alpha_{k}\left\|x_{k}\right\|^{2}+\left(1-\alpha_{k}\right)\left\|T_{i_{k}} x_{k}\right\|^{2} \\
& =\alpha_{k}\left(\|p\|^{2}-2\left\langle p, J x_{k}\right\rangle+\left\|x_{k}\right\|^{2}\right)+\left(1-\alpha_{k}\right)\left(\|p\|^{2}-2\left\langle p, J T_{i_{k}} x_{k}\right\rangle+\left\|T_{i_{k}} x_{k}\right\|^{2}\right) \\
& =\alpha_{k} \phi\left(p, x_{k}\right)+\left(1-\alpha_{k}\right) \phi\left(p, T_{i_{k}} x_{k}\right) \\
& \leq \alpha_{k} \phi\left(p, x_{k}\right)+\left(1-\alpha_{k}\right) \phi\left(p, x_{k}\right) \\
& =\phi\left(p, x_{k}\right) .
\end{aligned}
$$

This implies that $F \subset C_{k}$. It follows from $x_{k}=\Pi_{k-1} x_{1}$ and Lemma 2.3 that

$$
\left\langle x_{k}-z, J x_{1}-J x_{k}\right\rangle \geq 0, \quad \forall z \in C_{k-1} \cap Q_{k-1} .
$$

Particularly,

$$
\left\langle x_{k}-z, J x_{1}-J x_{k}\right\rangle \geq 0, \quad \forall p \in F
$$

and hence $F \subset Q_{k}$, which yields that

$$
F \subset C_{k} \cap Q_{k}
$$

By induction, (3.4) holds. This implies that $\left\{x_{n}\right\}$ is well defined. It follows from the definition of $Q_{n}$ and Lemma 2.3 that $x_{n}=\Pi_{Q_{n}} x_{1}$. Since $x_{n+1}=\Pi_{n} x_{1} \in Q_{n}$, we have

$$
\phi\left(x_{n}, x_{1}\right) \leq \phi\left(x_{n+1}, x_{1}\right), \quad \forall n \geq 1 .
$$

Therefore, $\left\{\phi\left(x_{n}, x_{1}\right)\right\}$ is nondecreasing. Using $x_{n}=\Pi_{Q_{n}} x_{1}$ and Lemma 2.4, we have

$$
\phi\left(x_{n}, x_{1}\right)=\phi\left(\Pi_{Q_{n}} x_{1}, x_{1}\right) \leq \phi\left(p, x_{1}\right)-\phi\left(p, x_{n}\right) \leq \phi\left(p, x_{1}\right)
$$

for all $p \in F$ and for all $n \geq 1$, that is, $\left\{\phi\left(x_{n}, x_{1}\right)\right\}$ is bounded. Then

$$
\lim _{n \rightarrow \infty} \phi\left(x_{n}, x_{1}\right) \text { exists. }
$$


In particular, by (2.5), the sequence $\left\{\left(\left\|x_{n}\right\|-\left\|x_{1}\right\|\right)^{2}\right\}$ is bounded. This implies that $\left\{x_{n}\right\}$ is bounded. Note again that $x_{n}=\Pi_{Q_{n}} x_{1}$ and for any positive integer $k, x_{n+k} \in Q_{n+k-1} \subset Q_{n}$. By Lemma 2.4,

$$
\begin{aligned}
\phi\left(x_{n+k}, x_{n}\right) & =\phi\left(x_{n+k}, \Pi_{Q_{n}} x_{1}\right) \\
& \leq \phi\left(x_{n+k}, x_{1}\right)-\phi\left(\Pi_{Q_{n}} x_{1}, x_{1}\right) \\
& =\phi\left(x_{n+k}, x_{1}\right)-\phi\left(x_{n}, x_{1}\right) .
\end{aligned}
$$

By Lemma 2.2, we have, for any positive integers $m, n$ with $m>n$,

$$
g\left(\left\|x_{m}-x_{n}\right\|\right) \leq \phi\left(x_{m}, x_{n}\right) \leq \phi\left(x_{m}, x_{1}\right)-\phi\left(x_{n}, x_{1}\right)
$$

where $g:[0, \infty) \rightarrow[0, \infty)$ is a continuous, strictly increasing, and convex function with $g(0)=0$. Then the properties of the function $g$ yield that $\left\{x_{n}\right\}$ is a Cauchy sequence in $C$, so there exists an $x^{*} \in C$ such that

$$
x_{n} \longrightarrow x^{*} \quad(n \longrightarrow \infty)
$$

In view of $x_{n+1}=\prod_{n} x_{1} \in C_{n}$ and the definition of $C_{n}$, we also have

$$
\phi\left(x_{n+1}, y_{n}\right) \leq \phi\left(x_{n+1}, x_{n}\right), \quad \forall n \geq 1
$$

This implies that

$$
\lim _{n \rightarrow \infty} \phi\left(x_{n+1}, y_{n}\right)=\lim _{n \rightarrow \infty} \phi\left(x_{n+1}, x_{n}\right)=0
$$

It follows from Lemma 2.2 that

$$
\lim _{n \rightarrow \infty}\left\|x_{n+1}-y_{n}\right\|=\lim _{n \rightarrow \infty}\left\|x_{n+1}-x_{n}\right\|=0
$$

Since $J$ is uniformly norm-to-norm continuous on bounded sets, we have

$$
\lim _{n \rightarrow \infty}\left\|J x_{n+1}-J y_{n}\right\|=\lim _{n \rightarrow \infty}\left\|J x_{n+1}-J x_{n}\right\|=0 .
$$

On the other hand, we have, for each $n \geq 1$,

$$
\begin{aligned}
\left\|J x_{n+1}-J y_{n}\right\| & =\left\|J x_{n+1}-\left(\alpha_{n} J x_{n}+\left(1-\alpha_{n}\right) J T_{i_{n}} x_{n}\right)\right\| \\
& =\left\|\left(1-\alpha_{n}\right)\left(J x_{n+1}-J T_{i_{n}} x_{n}\right)-\alpha_{n}\left(J x_{n}-J x_{n+1}\right)\right\| \\
& \geq\left(1-\alpha_{n}\right)\left\|J x_{n+1}-J T_{i_{n}} x_{n}\right\|-\alpha_{n}\left\|J x_{n}-J x_{n+1}\right\|,
\end{aligned}
$$


and hence

$$
\left\|J x_{n+1}-J T_{i_{n}} x_{n}\right\| \leq \frac{1}{1-\alpha_{n}}\left\|J x_{n+1}-J y_{n}\right\|+\frac{\alpha_{n}}{1-\alpha_{n}}\left\|J x_{n}-J x_{n+1}\right\| .
$$

From (3.18) and $\lim \sup _{n \rightarrow \infty} \alpha_{n}<1$, we obtain that

$$
\lim _{n \rightarrow \infty}\left\|J x_{n+1}-J T_{i_{n}} x_{n}\right\|=0
$$

Since $J^{-1}$ is uniformly norm-to-norm continuous on bounded sets, we have

$$
\lim _{n \rightarrow \infty}\left\|x_{n+1}-T_{i_{n}} x_{n}\right\|=\lim _{n \rightarrow \infty}\left\|J^{-1}\left(J x_{n+1}\right)-J^{-1}\left(J T_{i_{n}} x_{n}\right)\right\|=0
$$

It follows from (3.17) that, as $n \rightarrow \infty$,

$$
\left\|x_{n}-T_{i_{n}} x_{n}\right\| \leq\left\|x_{n}-x_{n+1}\right\|+\left\|x_{n+1}-T_{i_{n}} x_{n}\right\| \longrightarrow 0
$$

Now, set $\mathcal{K}_{i}=\left\{k \geq 1: k=i+(m-1) m / 2, m \geq i, m \in \mathbb{Z}^{+}\right\}$for each $i \geq 1$. Note that $T_{i_{k}}=T_{i}$ whenever $k \in \mathcal{K}_{i}$. For example, by the definition of $\mathcal{K}_{1}$, we have $\mathcal{K}_{1}=\{1,2,4,7,11,16, \ldots\}$ and $i_{1}=i_{2}=i_{4}=i_{7}=i_{11}=i_{16}=\cdots=1$. Then it follows from (3.23) that

$$
\lim _{\mathcal{K}_{i} \ni k \rightarrow \infty}\left\|T_{i} x_{k}-x_{k}\right\|=0, \quad \forall i \geq 1
$$

Since $\left\{x_{k}\right\}_{k \in \mathcal{K}_{i}}$ is a subsequence of $\left\{x_{n}\right\},(3.14)$ implies that $x_{k} \rightarrow x^{*}$ as $\mathcal{K}_{i} \ni k \rightarrow \infty$. It immediately follows from (3.24) and the closedness of $T_{i}$ that $x^{*} \in F\left(T_{i}\right)$ for each $i \geq 1$, and hence $x^{*} \in F$. Furthermore, by (3.10),

$$
\phi\left(x_{*}, x_{1}\right)=\lim _{n \rightarrow \infty} \phi\left(x_{n}, x_{1}\right) \leq \phi\left(p, x_{1}\right), \quad \forall p \in F
$$

This implies that $x^{*}=\Pi_{F} x_{1}$. The proof is completed.

Remark 3.2. Note that the algorithm (3.1) is based on the projection onto an intersection of two closed and convex sets. An example [22] of how to compute such a projection is given as follows. 


\section{Dykstra's Algorithm}

Let $\Omega_{1}, \Omega_{2}, \ldots, \Omega_{p}$ be closed and convex subsets of $\mathbb{R}^{n}$. For any $i=1,2, \ldots, p$ and $x^{0} \in \mathbb{R}^{n}$, the sequences $\left\{x_{i}^{k}\right\}$ are defined by the following recursive formulae:

$$
\begin{gathered}
x_{0}^{k}=x_{p}^{k-1}, \\
x_{i}^{k}=P_{\Omega_{i}}\left(x_{i-1}^{k}-y_{i}^{k-1}\right), \quad i=1,2, \ldots, p, \\
y_{i}^{k}=x_{i}^{k}-\left(x_{i-1}^{k}-y_{i}^{k-1}\right), \quad i=1,2, \ldots, p,
\end{gathered}
$$

for $k=1,2, \ldots$ with initial values $x_{p}^{0}=x^{0}$ and $y_{i}^{0}=0$ for $i=1,2, \ldots, p$. If $\Omega:=\bigcap_{i=1}^{p} \Omega_{i} \neq \emptyset$, then $\left\{x_{i}^{k}\right\}$ converges to $x^{*}=P_{\Omega}\left(x^{0}\right)$, where $P_{\Omega}(x):=\arg \inf _{y \in \Omega}\|y-x\|^{2}$, for all $x \in \mathbb{R}^{n}$.

\section{Applications}

The so-called convex feasibility problem for a family of mappings $\left\{T_{i}\right\}_{i=1}^{\infty}$ is to find a point in the nonempty intersection $\bigcap_{i=1}^{\infty} F\left(T_{i}\right)$, which exactly illustrates the importance of finding fixed points of infinite families. The following example also clarifies the same thing.

Example 4.1. Let $E$ be a smooth, strictly convex, and reflexive Banach space, $C$ a nonempty and closed convex subset of $E$, and $\left\{f_{i}\right\}_{i=1}^{\infty}: C \rightarrow C$ a countable family of bifunctions satisfying the conditions: for each $i \geq 1$,

$\left(A_{1}\right) f_{i}(x, x)=0$;

$\left(A_{2}\right) f_{i}$ is monotone, that is, $f_{i}(x, y)+f_{i}(y, x) \leq 0$;

$\left(A_{3}\right) \lim \sup _{t \downarrow 0} f_{i}(x+t(z-x), y) \leq f_{i}(x, y) ;$

$\left(A_{4}\right)$ the mapping $y \mapsto f_{i}(x, y)$ is convex and lower semicontinuous.

A system of equilibrium problems for $\left\{f_{i}\right\}_{i=1}^{\infty}$ is to find an $x^{*} \in C$ such that

$$
f_{i}\left(x^{*}, y\right) \geq 0, \quad \forall y \in C, i \geq 1,
$$

whose set of common solutions is denoted by $E P:=\bigcap_{i=1}^{\infty} E P\left(f_{i}\right)$, where $E P\left(f_{i}\right)$ denotes the set of solutions to the equilibrium problem for $f_{i}(i=1,2, \ldots)$. It will be shown in Theorem 4.3 that such a system of problems can be reduced to approximation of some fixed points of a countable family of nonexpansive mappings.

Example 4.2 (see [23]). Let $r>0$. Define a countable family of mappings $\left\{T_{r, i}\right\}_{i=1}^{\infty}: E \rightarrow C$ as follows:

$$
T_{r, i}(x)=\left\{z \in C: f_{i}(z, y)+\frac{1}{r}\langle y-z, J z-J x\rangle \geq 0, \forall y \in C\right\}, \quad \forall i \geq 1
$$


Then we have that

(1) $\left\{T_{r, i}\right\}_{i=1}^{\infty}$ is a sequence of single-valued mappings;

(2) $\left\{T_{r, i}\right\}_{i=1}^{\infty}$ is a sequence of closed relatively quasi-nonexpansive mappings;

(3) $F:=\bigcap_{i=1}^{\infty} F\left(T_{r, i}\right)=E P$.

Now, we have the following result.

Theorem 4.3. Let $C, E$, and $\left\{\alpha_{n}\right\}$ be the same as those in Theorem 3.1. Let $\left\{f_{i}\right\}_{i=1}^{\infty}: C \rightarrow C$ be a countable family of bifunctions satisfying the conditions $\left(A_{1}\right)-\left(A_{4}\right)$. Let $\left\{T_{r, i}\right\}_{i=1}^{\infty}: E \rightarrow C$ be a countable family of mappings defined by (4.2). Let $\left\{x_{n}\right\}$ be the sequence generated by

$$
\begin{gathered}
x_{1} \in C, \quad C_{0}=Q_{0}=C \\
f_{i_{n}}\left(u_{n}, y\right)+\frac{1}{r}\left\langle y-u_{n}, J u_{n}-J x_{n}\right\rangle \geq 0, \quad \forall y \in C \\
y_{n}=J^{-1}\left(\alpha_{n} J x_{n}+\left(1-\alpha_{n}\right) J u_{n}\right) \\
C_{n}=\left\{z \in C_{n-1} \cap Q_{n-1}: \phi\left(z, y_{n}\right) \leq \phi\left(z, x_{n}\right)\right\} \\
Q_{n}=\left\{z \in C_{n-1} \cap Q_{n-1}:\left\langle x_{n}-z, J x_{1}-J x_{n}\right\rangle \geq 0\right\} \\
x_{n+1}=\Pi_{n} x_{1}, \quad \forall n \geq 1
\end{gathered}
$$

where $i_{n}$ satisfies the positive integer equation: $n=i+(m-1) m / 2(m \geq i, n=1,2, \ldots)$. If $F:=$ $\bigcap_{i=1}^{\infty} F\left(T_{r, i}\right) \neq \emptyset$, then $\left\{x_{n}\right\}$ strongly converges to $\Pi_{F} x_{1}$ which is a common solution of the system of equilibrium problems for $\left\{f_{i}\right\}_{i=1}^{\infty}$.

Proof. Since each $T_{r, i}$ is single-valued, $u_{n}=T_{r, i_{n}} x_{n}$ for all $n \geq 1$. In addition, we have pointed out in Example 4.2 that $F=E P$ and $\left\{T_{r, i}\right\}_{i=1}^{\infty}$ is a sequence of closed relatively quasinonexpansive mappings. Hence, (4.3) can be rewritten as follows:

$$
\begin{gathered}
x_{1} \in C, \quad C_{0}=Q_{0}=C ; \\
y_{n}=J^{-1}\left(\alpha_{n} J x_{n}+\left(1-\alpha_{n}\right) J T_{r, i_{n}} x_{n}\right), \\
C_{n}=\left\{z \in C_{n-1} \cap Q_{n-1}: \phi\left(z, y_{n}\right) \leq \phi\left(z, x_{n}\right)\right\} \\
Q_{n}=\left\{z \in C_{n-1} \cap Q_{n-1}:\left\langle x_{n}-z, J x_{1}-J x_{n}\right\rangle \geq 0\right\} \\
x_{n+1}=\prod_{n} x_{1}, \quad \forall n \geq 1 .
\end{gathered}
$$

Therefore, this conclusion can be obtained immediately from Theorem 3.1. 


\section{Acknowledgments}

The author is greatly grateful to the referees for their useful suggestions by which the contents of this article are improved. This study was supported by the General Project of Scientific Research Foundation of Yunnan University of Finance and Economics (YC2012A02).

\section{References}

[1] W. R. Mann, "Mean value methods in iteration," Proceedings of the American Mathematical Society, vol. 4, pp. 506-510, 1953.

[2] S. Reich, "Weak convergence theorems for nonexpansive mappings in Banach spaces," Journal of Mathematical Analysis and Applications, vol. 67, no. 2, pp. 274-276, 1979.

[3] H. H. Bauschke, E. Matoušková, and S. Reich, "Projection and proximal point methods: convergence results and counterexamples," Nonlinear Analysis. Theory, Methods \& Applications, vol. 56, no. 5, pp. 715-738, 2004.

[4] A. Genel and J. Lindenstrauss, "An example concerning fixed points," Israel Journal of Mathematics, vol. 22, no. 1, pp. 81-86, 1975.

[5] K. Nakajo and W. Takahashi, "Strong convergence theorems for nonexpansive mappings and nonexpansive semigroups," Journal of Mathematical Analysis and Applications, vol. 279, no. 2, pp. 372-379, 2003.

[6] Y. Su and X. Qin, "Monotone CQ iteration processes for nonexpansive semigroups and maximal monotone operators," Nonlinear Analysis. Theory, Methods E Applications, vol. 68, no. 12, pp. 36573664, 2008.

[7] I. Cioranescu, Geometry of Banach Spaces, Duality Mappings and Nonlinear Problems, vol. 62 of Mathematics and its Applications, Kluwer Academic Publishers Group, Dordrecht, The Netherlands, 1990.

[8] S. Reich, "Book Review: geometry of Banach spaces, duality mappings and nonlinear problems," American Mathematical Society, vol. 26, no. 2, pp. 367-370, 1992.

[9] S. Reich, "A weak convergence theorem for the alternating method with Bregman distances," in Theory and Applications of Nonlinear Operators of Accretive and Monotone Type, vol. 178 of Lecture Notes in Pure and Applied Mathematics, pp. 313-318, Dekker, New York, NY, USA, 1996.

[10] D. Butnariu, S. Reich, and A. J. Zaslavski, "Asymptotic behavior of relatively nonexpansive operators in Banach spaces," Journal of Applied Analysis, vol. 7, no. 2, pp. 151-174, 2001.

[11] F. Kohsaka and W. Takahashi, "Block iterative methods for a finite family of relatively nonexpansive mappings in Banach spaces," Fixed Point Theory and Applications, vol. 2007, Article ID 21972, 18 pages, 2007.

[12] S.-Y. Matsushita and W. Takahashi, "Weak and strong convergence theorems for relatively nonexpansive mappings in Banach spaces," Fixed Point Theory and Applications, no. 1, pp. 37-47, 2004.

[13] S.-Y. Matsushita and W. Takahashi, "A strong convergence theorem for relatively nonexpansive mappings in a Banach space," Journal of Approximation Theory, vol. 134, no. 2, pp. 257-266, 2005.

[14] S.-Y. Matsushita and W. Takahashi, "An iterative algorithm for relatively nonexpansive mappings by a hybrid method and applications," in Nonlinear Analysis and Convex Analysis, pp. 305-313, Yokohama Publishers, Yokohama, Japan, 2004.

[15] S. Plubtieng and K. Ungchittrakool, "Strong convergence theorems for a common fixed point of two relatively nonexpansive mappings in a Banach space," Journal of Approximation Theory, vol. 149, no. 2, pp. 103-115, 2007.

[16] X. Qin and Y. Su, "Strong convergence theorems for relatively nonexpansive mappings in a Banach space," Nonlinear Analysis. Theory, Methods E Applications, vol. 67, no. 6, pp. 1958-1965, 2007.

[17] K. Aoyama, Y. Kimura, W. Takahashi, and M. Toyoda, "Approximation of common fixed points of a countable family of nonexpansive mappings in a Banach space," Nonlinear Analysis. Theory, Methods $\mathcal{E}$ Applications, vol. 67, no. 8, pp. 2350-2360, 2007.

[18] W. Nilsrakoo and S. Saejung, "Strong convergence to common fixed points of countable relatively quasi-nonexpansive mappings," Fixed Point Theory and Applications, vol. 2008, Article ID 312454, 19 pages, 2008.

[19] W. Takahashi, Nonlinear Functional Analysis, Fixed Point Theory and Its Applications, Yokohama Publishers, Yokohama, Japan, 2000.

[20] S. Kamimura and W. Takahashi, "Strong convergence of a proximal-type algorithm in a Banach space," SIAM Journal on Optimization, vol. 13, no. 3, pp. 938-945, 2002. 
[21] Y. I. Alber, "Metric and generalized projection operators in Banach spaces: properties and applications," in Theory and Applications of Nonlinear Operators of Accretive and Monotone Type, vol. 178 of Lecture Notes in Pure and Applied Mathematics, pp. 15-50, Dekker, New York, NY, USA, 1996.

[22] J. P. Boyle and R. L. Dykstra, "A method for finding projections onto the intersection of convex sets in Hilbert spaces," in Advances in Order Restricted Statistical Inference, vol. 37 of Lecture Notes in Statistics, pp. 28-47, Springer, Berlin, Germany, 1986.

[23] E. Blum and W. Oettli, "From optimization and variational inequalities to equilibrium problems," The Mathematics Student, vol. 63, no. 1-4, pp. 123-145, 1994. 


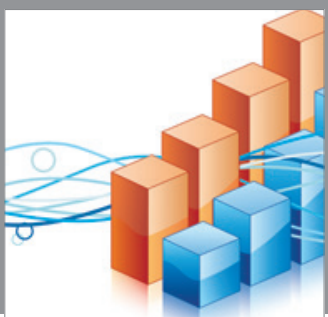

Advances in

Operations Research

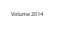

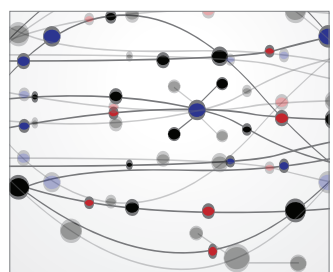

\section{The Scientific} World Journal
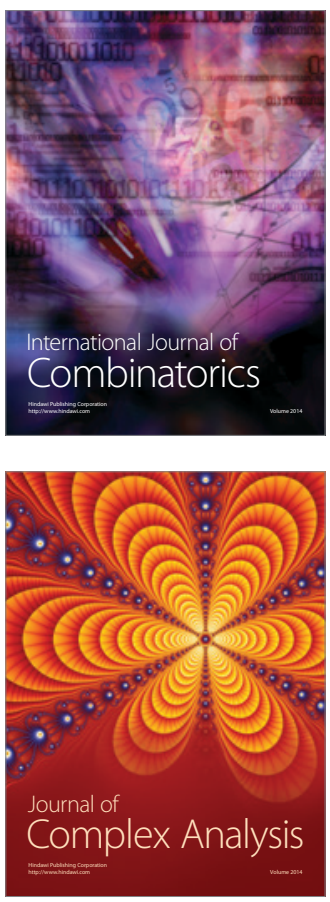

International Journal of

Mathematics and

Mathematical

Sciences
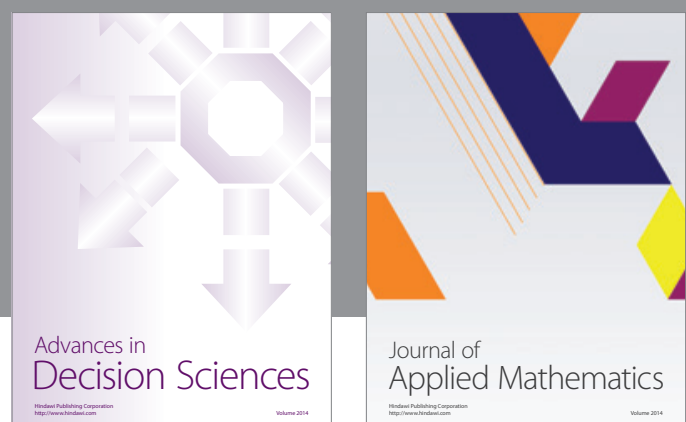

Journal of

Applied Mathematics
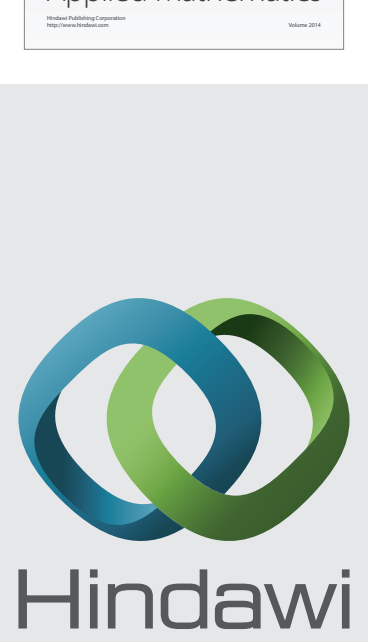

Submit your manuscripts at http://www.hindawi.com
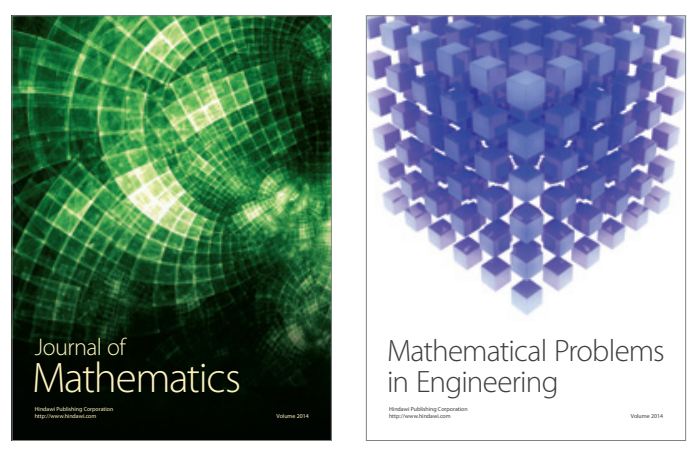

Mathematical Problems in Engineering
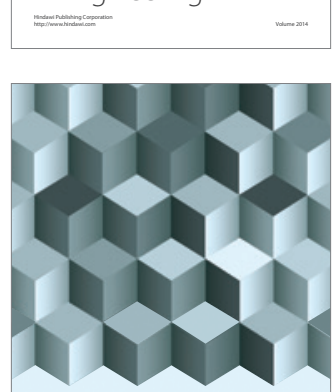

Journal of

Function Spaces
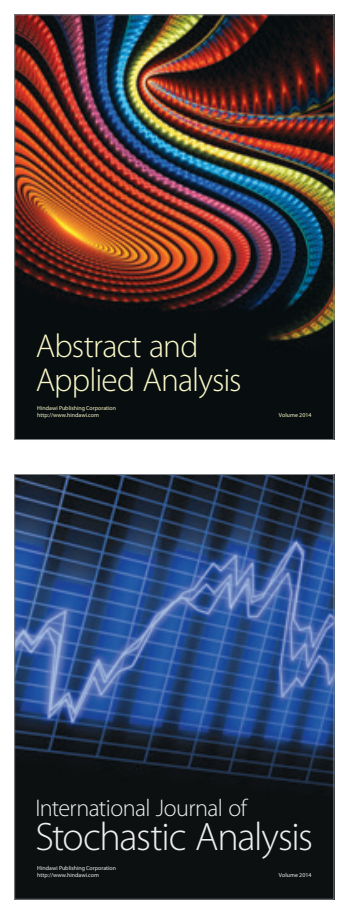

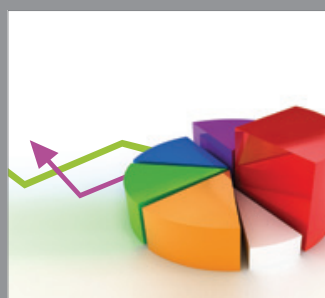

ournal of

Probability and Statistics

Promensencen
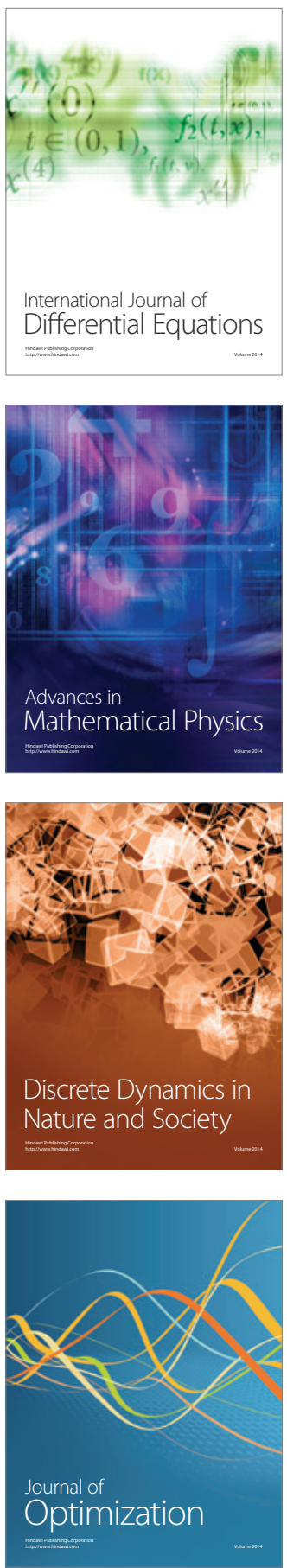